Association for Information Systems

AIS Electronic Library (AISeL)

\title{
New Workplace, New Mindset: Empirical Case Studies on the Interplay between Digital Workplace and Organizational Culture
}

Caterina Baumgartner

LMU Munich, Munich, Germany

Eva Hartl

LMU Munich, Munich, Germany

Thomas Hess

LMU Munich, Munich, Germany

Baumgartner, Caterina; Hartl, Eva; and Hess, Thomas, "New Workplace, New Mindset: Empirical Case Studies on the Interplay between Digital Workplace and Organizational Culture" (2021).

Wirtschaftsinformatik 2021 Proceedings. 6.

https://aisel.aisnet.org/wi2021/KDigitalEducation15/Track15/6

This material is brought to you by the Wirtschaftsinformatik at AIS Electronic Library (AISeL). It has been accepted for inclusion in Wirtschaftsinformatik 2021 Proceedings by an authorized administrator of AIS Electronic Library (AISeL). For more information, please contact elibrary@aisnet.org. 


\title{
New Workplace, New Mindset: Empirical Case Studies on the Interplay between Digital Workplace and Organizational Culture
}

\author{
Caterina Baumgartner ${ }^{1}$, Eva Hartl², Thomas Hess ${ }^{2}$ \\ 1,2 LMU Munich, Munich, Germany \\ 1 caterinabaumgartner@gmail.com \\ 2 hartl, thess\}@bwl.lmu.de
}

\begin{abstract}
Recently, firms have been observed to implement digital workplaces as strategic management tool to support their digital transformation. With this redesign of working environments, firms hope to foster their transformation by changing the organization's culture. With only little known on the impact of digital workplaces on cultural transformation, our study addresses this question and aims to disentangle the interplay of workplace redesign and culture. Based on the transformational journeys of four established firms, our study provides insights on the design of digital workplaces and derives a framework on the impact of digital workplaces on culture. Our results showcase best practices for an efficient design of digital workplaces and contribute to a better understanding of how digital workplaces foster cultural transformation.
\end{abstract}

Keywords: Digital Workplace, Workplace Transformation, Organizational Culture, Strategic Workplace Redesign

\section{Introduction}

“We shape our buildings, thereafter they shape us" - Winston Churchill, 1943

The redesign of workplaces as strategic management tool for steering organizational development has a long tradition [1]. However, in recent years in the context of digital transformation, new forms of strategic office redesign can be observed: Around the globe, firms have started to tear down walls and transform their workplaces into smart and agile work environments for knowledge workers [e.g. 2]. These so called "digital workplaces" are characterized by an increasingly digitized work environment that causes significant shifts in how work is conducted in organizations [3, 4], as well as an overall shift in organizational logics towards autonomy and creativity influenced by the New Ways of Working movement [5].

In the context of organizational digital transformation, firms were observed to experiment with the implementation of digital workplaces as strategic tool to support their organizational and cultural transformation [3, 6-9]. Within their digital transformation, firms essentially need to build capabilities for digital innovation in order to leverage value from new technologies [10]. However, recent research has 
emphasized the crucial importance of also considering transformations in organizations' socially constructed realities such as its identity [e.g. 11] or culture [e.g. 12, 13] and practitioners repeatedly stating culture as major hurdle for digital transformation [e.g. 14] support this claim. As one approach to steer an organization's culture change efforts towards a more fast-paced, agile, try-and-error and customercentric culture, firms have been found to increasingly implement digital workplaces in the hope that the redesigning of work environments will alter an organization's culture $[6,15]$. While first anecdotal narratives indeed suggest that digital workplaces can trigger cultural changes in form of increased employee connectedness, collaboration, and creativity [9, 16], only little is known on the impact of digital workplaces on cultural transformation. Prior research in the just emerging literature stream of digital workplaces predominantly took a technology-centric approach focusing on the promoted use of digital technologies and thereby covering only behavioral impacts of digital workplaces $[4,17]$. Indeed, workplace design research has been criticized for a general disregard of effects on organizational culture [18]. We aim to close this research gap by disentangling the interplay between physical workplace redesign and its impact on a social level, i.e. organizational culture. We therefore investigate digital workplaces under a holistic approach as the composition of place, technology and people and follow IS research in adopting a value-centric understanding of organizational culture. Specifically, our study addresses the question: How does the redesign of workplaces into digital workplaces impact cultural transformation?

We conducted qualitative case studies and investigated four firms, which had recently implemented new workplaces as part of their digital transformation, in order to identify common underlying characteristics of digital workplace designs and their impact on organizational culture. Our findings are presented in form of a comprehensive framework disentangling the interplay between digital workplaces and culture via identifying four impact paths. With our research, we pick up a recent research call on the future of work and digital transformation in organizations [19]. Our findings contribute to strategic workplace design research by shedding light on its impact on organizational culture and expand the body of knowledge on the micro-level of digital transformation [3] by exploring the impact of an individual's workplace environment on organizational culture change endeavors in the context of digital transformation. From a practitioner's point of view we manage to provide insights on actual workplace design and highlight the substantial role of culture in the context of workplace redesign.

\section{Theoretical Background}

\subsection{Digital Workplaces as Strategic Management Tool}

Workplace design has a long-standing tradition in ergonomics and human-oriented computer science [4]. However, with workplaces being at the center of an organization's cost savings strategy and the organization's visual representation, workplaces have also drawn interest in the fields of environmental psychology, corporate real estate, facility management and strategic management [1]. Research on 
organizational spaces as a strategic management tool has evolved since the early $20^{\text {th }}$ century, however with contemporary workplace strategies gaining more and more attention, practitioners and researchers alike have started to emphasize workplaces as a tool for steering organizational change and development [1]. Thus, it is hardly surprising that we see organizations experimenting with workplace redesign and transformation as a strategic tool to support their digital transformation [3, 6-8].

These recent developments in workplace strategic design are often termed as "digital workplaces" and are the results of two mega-trends. First, digital workplaces are heavily influenced by the New Ways of Working movement that led to a shift in organizational logics from control and function to autonomy and creativity [5]. In terms of organizational spaces, this implies that the future workplace "focuses on how and what work is done, not where and when it is done" [20, p.1]. Second, this shift in the nature of work has been enabled and pushed by today's work environment becoming predominantly digital [4]. The adoption of digital technologies facilitated communication and collaboration in novel and flexible ways and thereby caused significant shifts in how work is conducted in organizations [3, 4].

However, recent research emphasizes that the concept of digital workplaces requires a holistic approach, as the fundamentally different way of working induced by digital workplaces not only stems from the employment of digital technologies, but also the designing of physical spaces and behavioral norms that lead to new approaches to get things done [9]. Under this holistic approach that complement existing concepts of remote working or home office, digital workplaces constitute an intertwining of physical spaces, social systems and technology [21]. Recent digital workplace literature thus aligns with the concept of "Bricks, Bytes, and Behavior" from the new ways of working literature [16]. Following these triad-conceptualizations, we define digital workplaces as "the physical, technological and people-related arrangements that allow more flexible and collaborative ways of working to help organizations to cope with digital transformation." [9, p.136], as illustrated in Figure 1. That is, we understand place as "all aspects concerning the physical work environment, spaces, and facilities" [e.g. 16]. This component of digital workplaces is often designed in form of flexible and task-oriented office spaces with the aim to support employees best possible with the task at hand and include quiet areas, community areas, telephone boxes or recreational areas $[2,16]$. In this context, employees are also encouraged to work in different locations also outside the organization, e.g. at home or at the client. Secondly, technology refers to "all aspects of information technology usage within the company's digital ecosystem: Software, hardware, platforms, data and knowledge sharing" [e.g. 16]. The technology component of digital workplaces often contains tools and systems that shall drive a specific workstyle, e.g. innovation or knowledge sharing $[9,22]$. Without the technology and respective infrastructure, it would not be possible to achieve high levels of flexibility or collaboration at the workplace. In this context, cloud infrastructure and the rise of mobile devices can be seen as key enablers for digital workplaces [2]. Lastly, the people component comprises "all aspects of employee behavior, their skill set, or relation to each other" [e.g. 16] and becomes particularly important as firms require their employees to develop particular digital capabilities in order to succeed in dynamic environments. Consequently, this component is aimed to 
be designed in a way that shall drive employees' digital competences in form of new leadership styles, technical skills or collaboration forms [9, 22].

Digital Workplace

The physical, technological and people-related arrangements that allow more flexible and collaborative ways of working to help organizations to cope with digital transformation

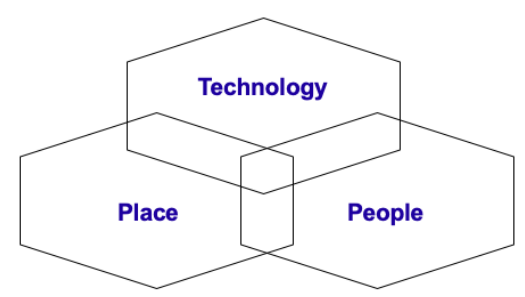

Figure 1. Conceptualization of digital workplace and its components

\subsection{Digital Workplaces and Culture Change}

An organization's digital transformation entails its strategic response to disruptions triggered by digital technologies that encompasses the alteration of an organization's value creation paths. Central to this transformation are digital innovations, i.e. leveraging digital technologies to alter an organization's portfolio of products, processes, and business models [10, 23]. Next to digital innovations, recent research emphasizes that also transformations in organizations' socially constructed realities such as its identity [e.g. 11] or culture [e.g. 12, 13] are of crucial importance for a successful digital transformation. Especially for the latter, organizations have rated culture as a major hurdle for digital transformation [e.g. 14]. Especially large pre-digital organizations built on long success roads that legitimize firm cultures of stability, operational excellence and organizational hierarchy, now struggle with the demands of digital innovation that require a more fast-paced, agile, try-and-error and customercentric approach $[7,8,12,13]$. As part of this digital culture change, firms have been observed to increasingly establish digital workplaces [6] in the hope that by redesigning work environments for knowledge workers also employees' mindset and thereby the organization's culture is altered [15].

The notion that changes in workplace design may lead to organizational changes is in line with Lefebvre's [24] view that social change is dependent on spatial change. However, a more moderate view is prevailing in recent workplace design research. This stream regards workplace redesigns as not necessarily creating organizational changes by themselves, but they may function as accelerator or reinforcement for the desired change [e.g. 25]. Consequently, also the implementation of digital workplaces has been found to lead to organizational changes in form of increased motivation and creativity of employees [16, 26], increased productivity, effectiveness, and engagement [7, 8]. Overall, digital workplaces were found to help firms succeed in the digital area by establishing the necessary capabilities and competences $[9,22]$. However, most studies in the just emerging research stream on digital workplaces are technology-centric and 
focus on the promoted use of digital technologies [4, 17], thereby mostly covering the visible and behavioral impacts of digital workplaces. Despite the implementation of digital workplaces being found to be a common tool in digital transformation efforts to enable culture change [6], only little is known about the impact of digital workplaces on a firm's culture. Indeed, the exact nature of the induced organizational changes by digital workplaces is still unclear [27].

This stands representative for an overall lacking focus of workplace design research on organizational culture, which is criticized for having for most parts disregarded the effect of workplace redesign on organizational culture [18]. Only few studies have examined this effect. For example, studies investigating the move to open offices found that such open office layouts led to an autonomous and less formal culture [28], increased cross-departmental collaboration and increased culture of learning [29]. While these studies illustrate ways in which office layouts can influence organizational culture, they solely focus on physical design elements of the workplace, omitting the increased importance of technologies.

Given the importance of organizational culture change for digital transformation and the observed efforts of firms to support this change via implementing digital workplaces, we aim to close this research gap and to shed light on the effects of digital workplace redesign on organizational culture. While definitions of organizational culture differ, it is generally understood to cover the shared meaning and understanding of organizational members of what is considered as norm [e.g. 30, 31]. This understanding of culture puts symbolic and implicit elements in the center of investigation. We follow the within IS discipline prevailing value-centric focus on organizational culture [32, 33] and investigate workplace induced changes in organizational culture in form of values. Values are defined as the shared beliefs of organizational members about what is considered as desirable, e.g. norms and ideals that impact the members' actions by setting expectations and boundaries for appropriate behavior [31,34]. We perceive this conceptualization of culture as necessary in order to be able to investigate the impacts of the physical (i.e. changes in workplace design in form of place, tools, and people) on the social (i.e. changes in cultural values). Some models of organizational culture like the three-layer pyramid model by Schein [31] comprise culture as both explicit and visible elements (e.g. artifacts such as behavior, language, symbols) as well as implicit aspects of culture (values and basic assumptions, which refer to the underlying belief system of unconscious, taken-for-granted beliefs). While we share their ontological view that the explicit and physical elements are representations of implicit elements and via realization become manifested as such, it is exactly these relations and influences that we aim to investigate and thus a clear-cut distinction between physical and social constructs is essential for our research.

\section{$3 \quad$ Methodological Approach}

Since digital workplaces are a rather new area of research and limited previous research is available, our study follows an exploratory approach. We chose a case study design, as case-study research allows for the investigation of recent phenomena in real-life 
context where boundaries are not clear. This approach further enables us to investigate both formal and informal processes. Specifically, we chose a multiple-case design which enables cross-case comparison, or more precisely results from one case can be compared and contrasted with the results of other cases [35]. To foster rigor, we followed common guidelines and recommendations for case study research $[35,36]$ to ensure the validity and reliability of our study.

\subsection{Case Selection and Data Collection}

For our multiple-case study, we studied four German firms that had recently undergone workplace transformation including physical and technological changes. The cases were sampled purposefully [37], with the aim to maximize diversity to allow for contrasting findings. We identified suitable research subjects by initial desk research on digital workplace implementation and further filtered for those that matched with our initial conceptualization of digital workplaces to end up with a final case selection that spans across different industries, firm sizes and business models.

Table 1. Overview on surveyed firms and data sources

\begin{tabular}{|c|c|c|c|c|}
\hline & Auto_Com & Auto_Club & $\begin{array}{c}\text { Financial } \\
\text { Services_Com }\end{array}$ & Software Com \\
\hline Industry & Automotive & $\begin{array}{c}\text { Transport and } \\
\text { Mobility }\end{array}$ & $\begin{array}{l}\text { Financial } \\
\text { Services }\end{array}$ & Software firm \\
\hline $\begin{array}{l}\text { Business } \\
\text { activity }\end{array}$ & $\begin{array}{l}\text { Automobile } \\
\text { manufacturer }\end{array}$ & $\begin{array}{c}\text { Mobility } \\
\text { association }\end{array}$ & $\begin{array}{l}\text { Asset manager } \\
\text { for } \\
\text { investments in } \\
\text { tangible assets }\end{array}$ & $\begin{array}{c}\text { Technology } \\
\text { company with } \\
\text { focus on hard- } \\
\text { and software }\end{array}$ \\
\hline Founded & 1909 & 1903 & 2007 & 1975 \\
\hline Headquarter & Germany & Germany & Germany & USA \\
\hline Legal form & $\begin{array}{c}\text { Stock } \\
\text { corporation }\end{array}$ & $\begin{array}{l}\text { Registered } \\
\text { association }\end{array}$ & $\begin{array}{c}\text { Stock } \\
\text { corporation }\end{array}$ & Corporation \\
\hline $\begin{array}{l}\text { Turnover } \\
2019\end{array}$ & 57 billion $€$ & 0,21 billion $€$ & $\begin{array}{l}0,16 \text { billion } € \\
\quad(2018)\end{array}$ & 125 billion $\$$ \\
\hline \# employees & 91.000 & 2900 & 730 & $\begin{array}{c}\text { 135.000 / } \\
\text { GER: } 2700\end{array}$ \\
\hline \# interviews & 3 & 5 & 3 & 3 \\
\hline $\begin{array}{l}\text { Interviewees } \\
\text { by position }\end{array}$ & $\begin{array}{l}\text { Head of IT for } \\
\text { Employee, } \\
\text { Project Lead HR } \\
\text { IT, 2x Manager } \\
\text { Planning } \\
\text { Department }\end{array}$ & $\begin{array}{l}\text { Chief Digital } \\
\text { Office, } \\
\text { Project Lead } \\
\text { Smart } \\
\text { Workplace, } \\
\text { 3x Referent } \\
\text { Digital } \\
\text { Workplaces }\end{array}$ & $\begin{array}{l}\text { Head of IT, } \\
\text { Head of } \\
\text { Digitalization, } \\
\text { Transformatio } \\
\text { n Manager }\end{array}$ & $\begin{array}{l}\text { IT Director, } \\
\text { Experience } \\
\text { Lead, } \\
\text { Digital } \\
\text { Marketing } \\
\text { Manager }\end{array}$ \\
\hline Secondary data & 30 pages & 13 pages & 8 pages & 72 pages \\
\hline
\end{tabular}


Overall, the acquired sample includes four firms located in the same geographical region that differ in size, industry, organizational context. To ensure construct validity and for the purpose of triangulation [35], we collected data on the cases in form of semistructured interviews and secondary data. Table 1 provides an overview of the cases and collected data. In order to obtain insights from different perspectives, we interviewed multiple experts per case with different professional backgrounds to avoid biases [38]. The interviews followed a semi-structured interview guideline [39] with sections on the firm's implementation of the digital workplace, its components and their design, as well as observed changes in organizational culture. Initial open questions allowed participants to openly share their experiences, with further sub-questions addressing themes and concepts identified in literature or that had emerged in the course of the first interviews. Overall, 14 interviews with 15 experts in both managerial and non-managerial positions were conducted via telephone or in person between Mai and July 2019. Our expert panel span across referents for digital workplaces without staff responsibility up to more senior team leads or C-level staff. The interviews ranged from 20 to 60 minutes, with an average interview length of 44 minutes. All interviews were conducted in German, were recorded - with permission of interviewees - and later transcribed, yielding 169 pages of verbatim reports. For triangulation purposes, we further collected secondary data in the form of company website information, blog and newspaper articles, press releases, and whitepaper on the digital workplaces of the case firms, resulting in an overall of 123 pages of secondary data. We obtained an initial understanding of the case firms' digital workplace design via secondary data and validated and extended these insights in the course of conducting interviews.

\subsection{Data Analysis}

The collected data was comprised within a case database [35] and stored as well as analyzed by using atlas.ti. The data was consequently coded in a combined deductive and inductive approach, considering themes and codes derived from literature findings and/or emerging from the data in the course of analysis [40]. First, our coding focused on a descriptive approach in order to derive insights on the design of digital workplace components, e.g. the quote: "From the very beginning we said very clearly that we no longer have any allocated workstations." was coded as "Place_Desk sharing concept". Further on, we drew on grounded theory [41] and iteratively went through our data to uncover interactions of digital workplaces and organizational culture as well as cultural changes. In refining our codes, we combed through our data at least three times and matched our codes with themes from literature [39]. For example, we drew from the organizational culture profile [34] as orientation to define cultural values.

The analysis of our coded data followed a two-step approach. First, we conducted within-case analysis to gain familiarity with data, identified constructs or relations within one firm and derived a detailed description of the firms' digital workplace and the associated cultural changes. In the subsequent cross-case analysis, we compared and contrasted findings from the cases to reveal similar constructs and relationships across the four firms - also referred to as pattern searching [42] and thereby derived a holistic framework on the interaction of digital workplaces and culture. The analysis 
was performed by two researchers and emerging differences were discussed bilaterally and resolved consensually [35]. Following triangulation principles, we reflected on our initial understanding of the case firms' workplace redesign from secondary data with additional information obtained from the interviews, and vice versa validated the insights gained in the course of conducting interviews with secondary data.

\section{$4 \quad$ Results}

\subsection{Within-Case Results}

In this section we present the results of our multiple-case study by outlining the introductions of digital workplaces in the four studied firms and describing the respective induced cultural changes.

Automotive_Com: Started their digital workplace initiative in 2011 by launching a series of digital innovations, amongst them "Enterprise 2.0" - their version of a collaborative software to simplify collaboration and enhance employee connectedness, which ensures consistent experience across multiple employee-led initiatives and consists of team workspaces, wikis, social networking and document sharing. Part of their digitalization strategy was also the implementation of flexible work arrangements such as home office regulations. Later on, a new office building was completed in 2016 in which modern office design came into place that features new rooms flooded with light, open space offices and communication areas. However, everyone still has assigned desks and home office regulations depend on respective departments due to company regulations. With regard to people, employees' attitude towards the modern workplace is two-fold with some leaders that prefer the presence of employees and do not encourage them to work remotely. The present hierarchical structures and leadership change slowly towards a supportive style as mutual trust is not always present. Hence, some employees do not participate in this new workstyle and some leaders still decide on extent and modalities of home office, whereas in some departments work is carried out more hierarchy- and organization-independent now, resulting in a culture with partially more openness and transparency.

Auto_Club: With the completion of their new headquarters in 2014, Auto_Club started their flex-office concept, which includes desk-sharing concept, clean desk policies, co-working spaces, a creative space and various home bases - in other words meeting rooms with writable walls. At the same time a "smart workplace" concept was introduced after having identified that hardware was not competitive for new ways of working. Subsequently, everyone across the firm was equipped with new laptops and a platform based on Microsoft Sharepoint for knowledge exchange and collaborative teamwork was established before finally launching Office 365 in 2019 to enable flexible working. People at Auto_Club are either very open or reluctant to the new workplace concept. Some stick with their fixed desks and thus hamper overall adoption of tools and facilities. Also, the perception of leadership has changed as more managers take on a more enabling role as "people managers". As a result, the firm culture benefits from higher levels of cooperation, innovation and trust. But due to opponents of the smart 
workplace concept, a divided firm culture can be observed, and beneficial cultural values occur slower.

Financial Services_Com: Quite recently at the beginning of 2019 they opened their "digital factory" - an innovation lab for a small fraction of employees from digital units and blueprint for future workplace transformation across the overall firm. For this purpose, an innovative room concept with group and quiet zones, open and closed meeting rooms, telephone boxes or lounge corners, where employees do not have assigned desks and rather choose the working environment that suits their task at hand, was established. Meeting rooms are equipped with touch screens and writable walls and innovative sensors monitor occupancy of rooms. Next to individual laptops and screens on every table, Microsoft 365 builds the foundation for collaborative teamwork and allows them to work jointly on documents or schedule project work. In accordance with new possibilities, members of the digital lab adopted an even more agile and flexible workstyle including daily standups or design thinking methodology. Leaders now have less administrative tasks and report faster decision making due to more proximity to employees. In this context also hierarchies have fully vanished, and the head of the digital unit says they even see themselves as a kind of "flatshare". As a consequence, employees are more confident and feel motivated. Even though a rather open mindset was already noticed before, cultural values such as innovation, mutual trust, flexibility and a culture where failure is seen as a chance have further evolved.

Software_Com: Introduced their "smart workspace" concept in 2016 with the move into their new headquarters. Trust-based working hours and home office had already been introduced at this point. The overall goal is the achievement of a work-life-flow in other words a self-determined design of daily tasks with flowing transitions between work and private life. Next to desk-sharing and clean desk policies, four zones to think, accomplish, share and discuss are part of the initiative and further telephone booths, coffee lounges and recreational areas complement the new room concept. Employees were equipped with latest collaborative tools and additional cloud technology or interactive whiteboard technology in meeting rooms allows them to work collaboratively. Hereby, dozens of applications are part of an ecosystem that also ensures compatibility. Regarding hardware, employees can decide whether to use firm or own devices. Moreover, being an American tech firm, culture has developed evolutionarily and has since ever been based on values such as trust and innovation. This fact and employee involvement during the planning phase led to high identification, satisfaction and acceptance with the new workspace. Even though employees can work from home any time, people tend to work at the new office because they benefit from the office surrounding and from both formal and informal exchange with colleagues, resulting in a more efficient workstyle where coordination and alignment happens faster. At the same time the leadership role has shifted towards an enabling style, where managers support by providing the right resources. All in all, the already existent values of openness, innovation and high levels of trust and teamwork were further reinforced through workplace transformation, as well as increased satisfaction and faster coordination could be observed in this course. 


\subsection{Cross-Case Results}

From our cross-case analysis, similarities and differences between the workplace designs of the cases and induced cultural changes emerge, as summarized in Table 2. With regard to workplace components, case firms introduced similar physical and technical advancements with the aim to support employees best possibly with their task at hand and encourage creativity, as Software_Com's Experience Lead underlines: "[...] only if the needs and requirements of people, space and technology are individually considered, the new work concept can unfold its full potential and enable innovation." However, different manifestations become visible, as physical office space and desk-sharing is less advanced at Auto_Com and Auto_Club and usage intensity of technical infrastructure differs from Software_Com and FS_Com. Nevertheless, interviews demonstrate that workstyles across all firms got more flexible with people switching locations, and more efficient as knowledge exchange and collaboration takes place more easily now which also facilitates organizational learning. Overall, despite different manifestations and approaches of digital workplaces among our case firms, cross-case results reveal that the firms approached their digital workplace design quite similarly.

With regard to our research question, cross-case analysis reveals that the introduction of digital workplaces induced cultural changes within the studied firms - particularly such concerning values of innovativeness, cooperation, and openness. Both, by introducing technological tools where employees simultaneously work together and by establishing a collaborative office environment, work processes and results become more transparent and knowledge sharing is facilitated, putting more emphasis on values like openness and transparency as we observed across all firms. More precisely, employees across our case firms now frequently encounter each other by switching workstations during the day, exchanging latest project insights and working within the same document. This also happens across hierarchies and consequently results in an increase of trust levels and openness. In this context, also Auto_Com mentions that integrity and transparency were fostered by transparent workstyles due to open office layout and document sharing: "We set great store [...] above all transparency [...]. I have to talk if something does not fit". These workplace advancements also lead to more exchange across hierarchies as "one speaks to each other independent of hierarchies and positions." [Project Lead HR IT, Auto_Com]. Overall, leaders particularly at Software_Com and FS_Com have high confidence in their team members and empower them. At Software_Com employees are encouraged to "[...] have more crazy ideas, ask more stupid questions." [Experience Lead]. Software_Com, which signals employees that risk-taking and failure is accepted and encouraged, observed increased trust levels and a cooperative teamwork culture: "Through this high sense of belonging $[\ldots]$ that of course everyone feels safe here and at eye level." [Digital Marketing Manager, FS_Com]. Since employees can now decide where, when and how they want to work e.g. by using creativity rooms and trying out new things, increased values of flexibility but also risk-taking and openness which are beneficial for development of new skills and in the long run innovations become visible. In contrast, the fact that people can now also work from the coffee bar at Auto_Com led 
to prejudices among reluctant employees: "They are just sitting around drinking coffee and "working" a little bit" [Project Lead HR IT]. Consequently, values associated with trust or flexibility are to some extent lower because of some reluctant members within Auto_Com or Auto_Club. All in all, our cases demonstrate that the individual components and particularly their interaction induce changes in cultural values. Additionally, it was noted that cultural changes are an ongoing process and might not yet be visible in some cases as the Chief Digital Officer at Auto_Club mentioned that they are "still far from being finished" with changing their culture.

Table 2. Cross-case results

\begin{tabular}{|c|c|c|c|c|}
\hline & Auto_Com & Auto_Club & $\begin{array}{c}\text { Financial } \\
\text { Services_Com }\end{array}$ & Software Com \\
\hline Place & $\begin{array}{l}\text { - Group offices } \\
\text { and few private } \\
\text { offices } \\
\text { - Coffee bar and } \\
\text { creative rooms } \\
\text { - Fixed desks }\end{array}$ & $\begin{array}{l}\text { - Group offices } \\
\text { and few private } \\
\text { offices } \\
\text { - Creative space } \\
\text { and zones } \\
\text { - Desk sharing but } \\
\text { resistance }\end{array}$ & $\begin{array}{l}\text { - Open office } \\
\text { - Open and closed } \\
\text { meeting rooms, } \\
\text { lounge areas } \\
\text { - Desk sharing }\end{array}$ & $\begin{array}{l}\text { - Open office, } \\
\text { creative and } \\
\text { recreational } \\
\text { spaces } \\
\text { - Dedicated work } \\
\text { zones } \\
\text { - Desk sharing }\end{array}$ \\
\hline \multicolumn{5}{|l|}{ Technology } \\
\hline Software & - Enterprise 2.0 & - Office 365 & - Office 365 & - Office 365 \\
\hline Hardware & $\begin{array}{l}\text { - Laptops for } \\
\text { majority of staff }\end{array}$ & $\begin{array}{l}\text { - Laptops for } \\
\text { majority of staff }\end{array}$ & $\begin{array}{l}\text { - Firm-wide } \\
\text { laptops and } \\
\text { phones }\end{array}$ & $\begin{array}{l}\text { - Firm-wide } \\
\text { laptops } \\
\text { - Bring your own } \\
\text { device }\end{array}$ \\
\hline Equipment & $\begin{array}{l}\text { - Screens and } \\
\text { click share in } \\
\text { meeting rooms }\end{array}$ & $\begin{array}{l}\text { - Screens, } \\
\text { whiteboards, } \\
\text { click share } \\
\text { technology }\end{array}$ & $\begin{array}{l}\text { - Sensors for room } \\
\text { utilization, } \\
\text { writable walls }\end{array}$ & $\begin{array}{l}\text { - Surface Hubs, } \\
\text { writable walls }\end{array}$ \\
\hline \multicolumn{5}{|l|}{ People } \\
\hline Acceptance & $\begin{array}{l}\text { - Partially } \\
\text { accepted }\end{array}$ & $\begin{array}{l}\text { - Partially } \\
\text { accepted }\end{array}$ & - Positive attitude & - Positive attitude \\
\hline $\begin{array}{l}\text { Behavior and } \\
\text { Skills }\end{array}$ & $\begin{array}{l}\text { - Increased } \\
\text { collaboration \& } \\
\text { communication }\end{array}$ & $\begin{array}{l}\text { - Increased } \\
\text { collaboration \& } \\
\text { communication }\end{array}$ & $\begin{array}{l}\text { - Firm-wide } \\
\text { collaboration } \\
\text { - Self-organized } \\
\text { learning } \\
\text { - Adoption of } \\
\text { agile methods }\end{array}$ & $\begin{array}{l}\text { - Firm-wide } \\
\text { collaboration } \\
\text { - Self-organized } \\
\text { learning } \\
\text { - Employment of } \\
\text { agile methods }\end{array}$ \\
\hline Workstyle & $\begin{array}{l}\text { - Partially flexible } \\
\text { and agile } \\
\text { workstyle } \\
\text { - Partially } \\
\text { increased } \\
\text { autonomy }\end{array}$ & $\begin{array}{l}\text { - Partially flexible } \\
\text { and agile } \\
\text { workstyle } \\
\text { - Partially } \\
\text { increased } \\
\text { autonomy }\end{array}$ & $\begin{array}{l}\text { - Flexible and } \\
\text { agile workstyle } \\
\text { across digital } \\
\text { factory } \\
\text { - Increased } \\
\text { autonomy \& } \\
\text { decision making }\end{array}$ & $\begin{array}{l}\text { - Flexible and } \\
\text { agile workstyle } \\
\text { across firm } \\
\text { - Autonomy \& } \\
\text { decision making }\end{array}$ \\
\hline Leadership & $\begin{array}{l}\text { - Slowly blurring } \\
\text { hierarchies }\end{array}$ & $\begin{array}{l}\text { - Slowly blurring } \\
\text { hierarchies }\end{array}$ & $\begin{array}{l}\text { - Enabling } \\
\text { leadership role }\end{array}$ & $\begin{array}{l}\text { - Enabling } \\
\text { leadership role }\end{array}$ \\
\hline $\begin{array}{l}\text { Cultural } \\
\text { Values }\end{array}$ & $\begin{array}{l}\text { - Openness } \\
\text { - Transparency } \\
\text { - Mutual trust } \\
\text { - Teamwork } \\
\text { Incremental } \\
\text { change }\end{array}$ & $\begin{array}{l}\text { - Flexibility } \\
\text { - Cooperation } \\
\text { - Participation } \\
\text { - Tolerance of } \\
\text { opponents } \\
\text { Incremental } \\
\text { change }\end{array}$ & $\begin{array}{l}\text { - Flexibility } \\
\text { - Risk taking } \\
\text { - Mutual trust } \\
\text { - Cooperation } \\
\text { Promotion of } \\
\text { existing values and } \\
\text { occurrence of new } \\
\text { values } \\
\end{array}$ & $\begin{array}{l}\text { - Flexibility } \\
\text { - Mutual trust } \\
\text { - Failure \& } \\
\quad \text { learning culture } \\
\text { Promotion of } \\
\text { existing values } \\
\text { and occurrence of } \\
\text { new values }\end{array}$ \\
\hline
\end{tabular}


However, while having identified similar organizational values across our firms, we found that these values were impacted in varying degrees. The differences in the intensity of cultural changes may be traced back to the firms' initial organizational culture and people-related elements. The cases of Auto_Com and Auto_Club, which were characterized by hierarchical structures, traditional workstyles, long tenure of employees and a leadership style that focuses on presence and expression of status: "[...] my house, my car, my horse, my private office" [Project Lead HR IT, Auto_Com] resulted in members showing resistance towards the digital workplace and thus a divided culture of opponents and supporters. In contrast Software_Com's culture has always been based on values such as trust, innovation and risk-taking - which is why they "probably have less hurdles than an established German carmaker" [IT Director, Software_Com]. Next to this initial effect of implemented digital workplaces on organizational culture, we observed a later-stage reverse effect of the newly induced culture on the digital workplaces - particularly within the people dimension. As a consequence of the increased levels of mutual trust and appreciation that are present now at Software_Com and FS_Com, interviewees report that employees are more satisfied and motivated as they can now self-determine the modalities of their work, as the following quote reflects: "So it definitely makes me more satisfied and I think the majority of employees [...] as well." [IT Director, Software_Com]. At this point it should also be mentioned that interviewees emphasized the role of management commitment and change management initiatives for adoption and success of workplace transformation.

\section{Discussion}

Our results not only provide a detailed overview of digital workplace design and its components, but also highlight the importance of taking on a comprehensive approach towards digital workplaces as we found many elements of digital workplaces to be heavily interrelated. Our cases demonstrate that collaboration was facilitated by new technical introductions and a change in people's workstyle came along that however also required a new skillset. As one example, the availability of white boards or document sharing on the one hand requires a certain technical skillset and on the other hand supports employees in working collaboratively within one document or project and affects their workstyle in terms of transparency and collaboration. Furthermore, the new technologies are reconciled with the physical surrounding itself as FS_Com and Software_Com demonstrate with smart tables that can be controlled via smartphone. Our results further show that interrelations and dependencies amongst digital workplace components impact workplace effectiveness. In this context, the fact that remote working at Auto_Com depends on respective leaders, led to a rather immature version of digital workplaces.

With regard to the impact of digital workplaces on organizational culture, our results show that the implementation of digital workplaces triggers changes in an organization's values (a), but that the maturity of digital workplaces and resulting intensity of cultural changes is dependent on the prevailing underlying assumptions 
within organizations (b), and the organization's capability to overcome them, e.g. by supporting change management efforts (c). In turn, the resulting cultural changes from digital workplace implementation may again impact especially the people-related aspects of digital workplaces (d). These relations between digital workplace implementation and organizational culture are summarized in Figure 2.

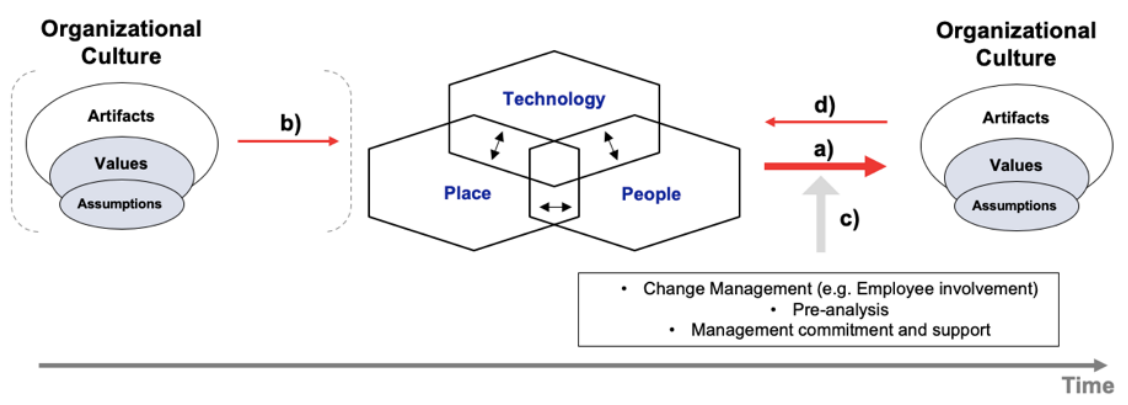

Figure 2. Holistic framework on digital workplaces and organizational culture

First of all, our cases confirm that digital workplaces and their components indeed affect organizational culture (depicted as effect a). One could argue that physical and technical changes in context of digital workplaces happen on an artifact level as they are rather visible and then affect implicit values. More precisely, the new possibilities enabled by technical and spatial aspects on artifact level, have impact on cultural values in several ways: Employees can now autonomously decide on work location inside and outside the office and they have a variety of technical tools and work environments that support them, which also affects their workstyle and skillset. Not only will their workstyle become more independent, they will feel empowered because they are granted confidence and have room for creativity. However, if people appreciate this flexibility and if mutual trust among leaders and employees exists, the organizational culture can benefit from increased flexibility and openness (on value level). In our cases, values associated with flexibility (e.g. openness), teamwork and cooperation could be increased with the implementation of digital workplaces. These results support earlier research findings [15] that in line with our results also found digital workplaces to promote creativity and innovation [e.g. 43].

However, despite similarities in workplace design and overall identified cultural values, intensity level and manifestation of values differ between firms. A phenomenon which was also noted by previous research findings [44]. One could argue that basic assumptions such as mutual trust, high esteem and benevolent relations, which were present at Software_Com and FS_Com, are a reason why we have observed higher levels of flexibility and teamwork compared to other cases. Consequently, we observed leaders who support employees regarding goal achievement and work organization, strong team spirit as well as high overall adoption and identification with digital workplaces. In contrast, the reason for high resistance among leaders and employees at Auto_Com and Auto_Club could lie in prevailing basic assumptions that are more dedicated to control mechanisms and hierarchical relationships. In summary, our results point to three suggestions regarding the role of initial firm culture (depicted as effect b). The larger the gap between initial culture and pursued beneficial culture of 
innovation and flexibility, 1) the longer it takes until favorable outcomes in values are observed and/or 2) the lower the intensity level of cultural values after transformation and/or 3) the more likely the resistance of employees. In any event, these proposed effects require further research.

Moreover, our interview partners pointed out several moderating factors that support the cultural impact of digital workplace implementation (depicted as effect c). Especially when prevailing basic assumptions are misaligned with the implemented digital workplaces and their targeted values, change management initiatives are required to bridge this cultural divide. A participative approach present at Software_Com with employees "co-creating" the new workplace, has therefore been found to be beneficial in managing resistance and thus employees should be integrated in change initiatives as early as possible [45]. Furthermore, our results confirm previous findings on the importance of leadership for employee commitment: A transformational leadership style increases commitment of followers [46].

Lastly, our analysis also reveals that cultural values, induced by digital workplaces again interact with digital workplace components (depicted as effect d). As one example, the promoted participative leadership style again reinforces mutual trust within the firm. This reiterative interaction and longitudinal adjustment process between digital workplace and culture also is in line with Dery et al.'s [9] call for systemic learning and continuous feedback as essential elements for a successful implementation of digital workplaces.

\section{Implications, Limitations and Future Research}

The results of our multiple-case study show that the implementation of digital workplaces indeed lead to changes in organizational culture and foster values of flexibility, openness, teamwork and cooperation, creativity, and innovation. However, the maturity of digital workplaces and resulting intensity of cultural changes is dependent upon the prevailing underlying assumptions within organizations and their capability to overcome them. Our results further suggest a continuous adaptation between digital workplaces and culture, as induced cultural changes again support the people-component of digital workplaces.

By disentangling the complex interplay between digital workplaces and cultural transformation, our results contribute to strategic workplace design research by closing the existing research gap on the impact of workplace redesign on culture. Further, we contribute to the body of knowledge on the micro-level of digital transformation [3] by exploring the impact of individual workplace environments on organizational culture change endeavors in the context of digital transformation. The understanding of this relationship is crucial for impactful digital workplaces, as the success of digital workplace transformation is essentially dependent on culture. Moreover, our research sheds light on the actual design of digital workplaces thereby addressing the ongoing struggle of organizations in how to design their digital workplaces [17]. With our holistic approach, we enrich literature with a detailed account of four digital workplaces and their technological, physical and people-related components. From a practitioner's point of view, we manage to offer recommendations and best practices for practitioners 
in designing their digital workplace strategy. Further, our derived framework enables us to explain why similar arrangements in workplace initiatives lead to diverse cultural outcomes and might thus offer guidance for practitioners implementing digital workplaces. We further highlight the importance of change management, strategy development and employee integration for successful digital workplaces.

Next to these contributions, we need to point out some limitations of our study. While our qualitative approach allowed us to uncover interactions between digital workplaces and culture, it comes with the general limitation of qualitative research of lacking generalizability due to a small number of investigated cases. Future quantitative research might thus validate our results and also quantitatively assess the effect of digital workplace implementation on culture. Second, we studied firms that recently have implemented digital workplaces. To avoid biases from "honeymoon effects" [47], future research is encouraged to conduct longitudinal studies in order to assess longterm effects and to gain more detailed insights into how cultural changes evolve over time. Third, our study focused on the impacts of digital workplaces on culture. But as our results suggest, this interplay is more complex so future research might extend our framework by studying further moderating and mediating factors, as well as extend the scope of digital workplace impact. Lastly, our findings are based on interviews with rather managerial staff and may lack an employee perspective on cultural changes. While we are confident that our results also cover the employee perception as some of our interview partners were still on a lower seniority level without staff responsibility (thus can be considered as employees themselves), future research is encouraged to a stronger focus on non-executive levels when investigating the impacts of digital workplaces on culture.

Despite the mentioned limitations, we believe our holistic framework manages to enrich our understanding of the role culture plays in workplace transformation and gives valuable insights on actual digital workplace design. Importantly, it could be demonstrated that a new workplace does not necessarily change organizational culture but rather is a complex process of reciprocal changes that requires ongoing leadership and change management support.

\section{References}

1. Skogland, M.A.C., Hansen, G.K.: Change Your Space, Change Your Culture: Exploring Spatial Change Management Strategies. Journal of Corporate Real Estate 19, 95-110 (2017)

2. Microsoft: The New World of Work. A Competitive Advantage for Irish Business., (2005)

3. Meske, C., Junglas, I.: Investigating the Elicitation of Employees' Support Towards Digital Workplace Transformation. Behaviour \& Information Technology 39, 1-17 (2020)

4. Richter, A., Heinrich, P., Stocker, A., Schwabe, G.: Digital Work Design. Business \& Information Systems Engineering 60, 259-264 (2018)

5. Kingma, S.: New Ways of Working (NWW): Work Space and Cultural Change in Virtualizing Organizations. Culture and Organization 25, 383-406 (2019)

6. Hartl, E.: A Characterization of Culture Change in the Context of Digital Transformation. In: 25th Americas Conference on Information Systems, Cancún (2019) 
7. Colbert, A., Yee, N., George, G.: The Digital Workforce and the Workplace of the Future. Academy of Management Journal 59, 731-739 (2016)

8. Kaarst-Brown, M.L., Quesenberry, J., Niederman, F., Weitzel, T.: Editors' Comments: Special Issue Editorial: New Approaches to Optimizing the Digital Workplace. MIS Quarterly Executive 17, 9-23 (2018)

9. Dery, K., Sebastian, I.M., van der Meulen, N.: The Digital Workplace is Key to Digital Innovation. MIS Quarterly Executive 16, 135-152 (2017)

10. Vial, G.: Understanding Digital Transformation: A Review and a Research Agenda. The Journal of Strategic Information Systems 28, 118-144 (2019)

11. Wessel, L., Baiyere, A., Ologeanu-Taddei, R., Cha, J., Blegind Jensen, T.: Unpacking the Difference between Digital Transformation and IT-enabled Organizational Transformation. Journal of the Association for Information Systems (2020)

12. Bilgeri, D., Wortmann, F., Fleisch, E.: How Digital Transformation Affects Large Manufacturing Companies' Organization. In: Thirty Eighth International Conference on Information Systems, 1-9, South Korea (2017)

13. Hartl, E., Hess, T.: The Role of Cultural Values for Digital Transformation: Insights from a Delphi Study. In: Twenty-third Americas Conference on Information Systems, 1-10, Boston (2017)

14. Capgemini: The Digital Culture Challenge: Closing the Employee-Leadership Gap. https://www.capgemini.com/fi-en/wp-content/uploads/sites/27/2018/09/dtidigitalculture_report_v2.pdf (2018).

15. van Heck, E., van Baalen, P., van der Meulen, N., van Oosterhout, M.: Achieving High Performance in a Mobile and Green Workplace: Lessons from Microsoft Netherlands. MIS Quarterly Executive 11, 175-188 (2012)

16. de Kok, A.: The New Way of Working: Bricks, Bytes \& Behavior. In: Lee, J. (ed.) The Impact of ICT on Work pp. 9-40. Springer, Singapore (2016)

17. Köffer, S.: Designing the Digital Workplace of the future - What Scholars Recommend to Practitioners. In: Thirty Sixth International Conference on Information Systems, 1-21, Fort Worth (2015)

18. Zerella, S., Von Treuer, K., Albrecht, S.L.: The Influence of Office Layout Features on Employee Perception of Organizational Culture. Journal of Environmental Psychology 54, 1-10 (2017)

19. Baptista, J., Stein, M.-K., Lee, J., Watson-Manheim, M.B., Klein, S.: Call for Papers: Strategic Perspectives on Digital Work and Organizational Transformation Special Issue The Journal of Strategic Information Systems (2017)

20. Dittes, S., Richter, S., Richter, A., Smolnik, S.: Toward the Workplace of the Future: How Organizations Can Facilitate Digital Work. Business Horizons 62, 649-661 (2019)

21. Kane, G.: The Workplace of the Future: Digital Technology Is Transforming Even Our Physical Work Spaces. MIT Sloan Management Review 56, 1-8 (2015)

22. Kissmer, T., Knoll, J., Stieglitz, S., Groß, R.: Knowledge Workers' Expectations Towards a Digital Workplace. In: Twenty-fourth Americas Conference on Information Systems, 1-10, New Orleans (2018)

23. Hess, T., Matt, C., Benlian, A., Wiesböck, F.: Options for Formulating a Digital Transformation Strategy. MIS Quarterly Executive 15, 123-139 (2016)

24. Lefebvre, H., Nicholson-Smith, D.: The Production of Space. Oxford Blackwell (1991)

25. Tanis, J.: Workspace and Behavior. In: Kuttner, P., Grech, C., Walters, D. (eds.) Future office: Design, Practice and Applied Research Routledge, London (2008)

26. Amabile, T.M., Conti, R., Coon, H., Lazenby, J., Herron, M.: Assessing the Work Environment for Creativity. The Academy of Management Journal 39, 1154-1184 (1996) 
27. Schwarzmüller, T., Brosi, P., Duman, D., Welpe, I.M.: How Does the Digital Transformation Affect Organizations? Key Themes of Change in Work Design and Leadership. Management Revue 29, 114-138 (2018)

28. McElroy, J.C., Morrow, P.C.: Employee Reactions to Office Redesign: A Naturally Occurring Quasi-field Experiment in a Multi-generational Setting. Human Relations 63, 609-636 (2010)

29. Hong, J.F., Easterby-Smith, M., Snell, R.S.: Transferring Organizational Learning Systems to Japanese Subsidiaries in China. Journal of Management Studies 43, 1027-1058 (2006)

30. Alvesson, M., Sveningsson, S.: Changing Organizational Culture: Cultural Change Work in Progress. Routledge (2015)

31. Schein, E.H.: Organizational Culture. American Psychologist 45, 109-119 (1990)

32. Tams, S.: Moving Cultural Information Systems Research Toward Maturity. Information Technology \& People 26, 383-400 (2013)

33. Leidner, D.E., Kayworth, T.: Review: A Review of Culture in Information Systems Research: Toward a Theory of Information Technology Conflict. MIS Quarterly 30, 357399 (2006)

34. O'Reilly III, C.A., Chatman, J., Caldwell, D.F.: People and Organizational Culture: A Profile Comparison Approach to Assessing Person-Organization Fit. Academy of Management Journal 34, 487-516 (1991)

35. Yin, R.K.: Case Study Research: Design and Methods. Sage, Thousand Oaks, CA (2014)

36. Koners, U., Goffin, K.: Learning from Postproject Reviews: A Cross Case Analysis. Journal of Product Innovation Management 24, 242-258 (2007)

37. Patton, M.Q.: Two Decades of Developments in Qualitative Inquiry: A Personal, Experiential Perspective. Qualitative Social Work 1, 261-283 (2002)

38. Choudrie, J., Papazafeiropoulou, A., Lee, H.: A Web of Stakeholders and Strategies: A Case of Broadband Diffusion in South Korea. Journal of Information Technology 18, 281-290 (2003)

39. Myers, M.D.: Qualitative Research in Business and Management. Sage Publications Thousand Oaks, CA (2009)

40. Ryan, G.W., Bernard, H.R.: Data Management and Analysis Methods. In: Densin, N.K., Lincoln, Y.S. (eds.) Handbook of Qualitative Research, pp. 769-802. SAGE Publications, Thousand Oaks, C (2000)

41. Glaser, B.G., Strauss, A.L.: Discovery of Grounded Theory: Strategies for Qualitative Research. Routledge, New York (1967)

42. Graebner, M.E., Eisenhardt, K.M.: The Seller's Side of the Story: Acquisition as Courtship and Governance as Syndicate in Entrepreneurial Firms. Administrative Science Quarterly 49, 366-403 (2004)

43. Martins, E.C., Terblanche, F.: Building Organisational Culture that Stimulates Creativity and Innovation. European Journal of Innovation Management 6, 64-74 (2003)

44. Klein, K.J., Sorra, J.S.: The Challenge of Innovation Implementation. Academy of Management Review 21, 1055-1080 (1996)

45. Waddell, D., Sohal, A.S.: Resistance: A Constructive Tool for Change Management. Management Decision 36, 543-548 (1998)

46. Abrell-Vogel, C., Rowold, J.: Leaders' Commitment to Change and Their Effectiveness in Change - a Multilevel Investigation. Journal of Organizational Change Management 27, 900-921 (2014)

47. Wohlers, C., Hertel, G.: Longitudinal Effects of Activity-Based Flexible Office Design on Teamwork. Frontiers in Psychology 9, 1-16 (2018) 